\title{
Cytoplasmic localization of alteration/deficiency in activation 3 (ADA3) predicts poor clinical outcome in breast cancer patients
}

\author{
Sameer Mirza $\cdot$ Emad A. Rakha $\cdot$ Alaa Alshareeda $\cdot$ Shakur Mohibi $\cdot$ \\ Xiangshan Zhao $\cdot$ Bryan J. Katafiasz $\cdot$ Jun Wang $\cdot$ Channabasavaiah Basavaraju Gurumurthy \\ Aditya Bele · Ian O. Ellis · Andrew R. Green · Hamid Band • Vimla Band
}

Received: 6 October 2012/ Accepted: 27 November 2012/Published online: 4 January 2013

(C) The Author(s) 2013. This article is published with open access at Springerlink.com

\begin{abstract}
Transcriptional activation by estrogen receptor (ER) is a key step to breast oncogenesis. Given previous findings that ADA 3 is a critical component of HAT complexes that regulate ER function and evidence that overexpression of other ER coactivators such as SRC-3 is associated with clinical outcomes in breast cancer, the current study was designed to assess the potential significance of ADA3 expression/ localization in human breast cancer patients. In this study, we analyzed ADA3 expression in breast cancer tissue specimens and assessed the correlation of ADA3 staining with cancer progression and patient outcome. Tissue microarrays prepared from large series of breast cancer patients with long-term follow-ups were stained with anti-ADA3 monoclonal antibody using immunohistochemistry. Samples were analyzed for ADA3 expression followed by correlation with various clinicopathological parameters and patients' outcomes. We report that breast cancer specimens show predominant
\end{abstract}

Electronic supplementary material The online version of this article (doi:10.1007/s10549-012-2363-3) contains supplementary material, which is available to authorized users.

S. Mirza $\cdot$ S. Mohibi $\cdot$ X. Zhao $\cdot$ B. J. Katafiasz $\cdot$ J. Wang

C. B. Gurumurthy · A. Bele $\cdot$ H. Band · V. Band ( $\square)$

Department of Genetics, Cell Biology \& Anatomy,

University of Nebraska Medical Center, Omaha,

NE 68198-5805, USA

e-mail: vband@unmc.edu

E. A. Rakha - A. Alshareeda - I. O. Ellis - A. R. Green

School of Molecular Medical Sciences and Cellular Pathology,

University of Nottingham and Nottingham University Hospital,

Nottingham City Hospital, Hucknall Road,

Nottingham NG5 1PB, UK

H. Band

Department of Biochemistry \& Molecular Biology,

University of Nebraska Medical Center, Omaha,

NE 68198-5805, USA nuclear, cytoplasmic, or mixed nuclear + cytoplasmic ADA3 staining patterns. Predominant nuclear ADA3 staining correlated with $\mathrm{ER}+$ status. While predominant cytoplasmic ADA3 staining negatively correlated with ER+ status, but positively correlated with ErbB2, EGFR, and Ki67. Furthermore, a positive correlation of cytoplasmic ADA3 was observed with higher histological grade, mitotic counts, Nottingham Prognostic Index, and positive vascular invasion. Patients with nuclear ADA3 and ER positivity have better breast cancer specific survival and distant metastasis free survival. Significantly, cytoplasmic expression of ADA3 showed a strong positive association with reduced BCSS and DMFS in ErbB2+/EGFR + patients. Although in multivariate analyses ADA3 expression was not an independent marker of survival, predominant nuclear ADA3 staining in breast cancer tissues correlates with ER+ expression and together serves as a marker of good prognosis, whereas predominant cytoplasmic ADA3 expression correlates with ErbB2+/EGFR+ expression and together is a marker of poor prognosis. Thus, ADA3 cytoplasmic localization together with ErbB2+/

\author{
H. Band \\ Department of Pathology \& Microbiology, \\ University of Nebraska Medical Center, Omaha, \\ NE 68198-5805, USA \\ H. Band \\ Department of Pharmacology \& Experimental Neuroscience, \\ College of Medicine, University of Nebraska Medical Center, \\ Omaha, NE 68198-5805, USA \\ H. Band · V. Band \\ Eppley Institute for Research in Cancer and Allied Diseases, \\ University of Nebraska Medical Center, \\ Omaha, NE 68198-5805, USA
}


EGFR+ status may serve as better prognostic marker than individual proteins to predict survival of patients.

Keywords ADA3 - STAGA - ATAC - Coactivator . ErbB2 $\cdot$ ER $\cdot$ PR $\cdot$ Breast cancer

\section{Introduction}

With an estimated 230,480 new cases in the year 2011, and 39,520 of them fatal, breast cancer remains the most common malignancy and the second leading cause of cancerrelated deaths among women in the U.S. [1]. A combination of markers based on breast cancer pathogenesis has led to the classification of breast cancers into different subtypes that are associated with distinct patient outcomes. Thus, estrogen receptor (ER) and progesterone receptor (PR) positive $(\mathrm{ER}+/ \mathrm{PR}+)$ luminal type of breast cancers are amenable to hormonal therapy and show a substantially better outcome [2]. In contrast, HER2/ErbB2-overexpressing and typically ER/PR-negative luminal breast cancers fail to respond to hormonal therapy and show substantially poorer outcomes compared to $\mathrm{ER}+/ \mathrm{PR}+$ patients. This subtype of patients, however, selectively benefit from ErbB2-directed targeted therapies such as Trastuzumab [3].

Our initial focus on ADA3 stemmed from the wellaccepted role of the hormonal history of a woman as a determinant of her lifetime risk of developing breast cancer [4]: the well-established pro-oncogenic role of estrogens in animal models $[5,6]$ and the linkage of environmental estrogens to increased risk of breast and other cancers [4]. These effects are thought to be mediated predominantly by ERs.

ERs function as ligand-activated transcription factors and known ER targets include genes, such as c-myc, PR, cyclin D1, and TGF $\alpha$, linked to promotion of cell proliferation and other oncogenic traits such as cell motility and invasion [7-9]. Similar to other transcriptional activators, the ER-dependent gene transcription requires interaction of ERs with transcriptional co-regulators, such as steroid receptor coactivators (SRCs) [10-13] and co-integrators, such as p300/CBP [14, 15]. The importance of transcriptional co-regulators is emphasized by the requirement of SRC-3 in development and estrogenic response of the mammary gland in mice $[16,17]$ and by studies demonstrating that overexpression of SRC-3 in human breast cancer cell lines and patient tumors is associated with resistance to anti-estrogen therapy [18]. These studies provided a strong rationale to investigate the expression of the novel ER coactivator alteration/deficiency in activation (ADA3) in breast cancer.

ADA3 is an essential adaptor component of ADA histone acetyltransferase (HAT) complex initially identified in yeast where it bridges transcription factor interacting component ADA2 with HAT enzymatic component GCN5. Mammals possess several distinct ADA3-containing HAT complexes with different subunit composition and multiple HAT enzymatic components including GCN5, PCAF, and p300/CBP [19]. We previously showed that human ADA3 directly interacts with $\mathrm{ER} \alpha$, and chromatin immunoprecipitation analyses demonstrated that ADA3 is a component of ER-associated HAT complexes bound to native promoter of the estrogen-responsive gene $\operatorname{pS} 2$ [20, 21]. Using RNAi knockdown, we demonstrated that endogenous ADA3 was required for estrogen-induced increase in the expression of widely studied ER-responsive target genes such as pS2, cathepsin D, and PR [20, 21].

The current study was designed to assess the potential significance of ADA3 expression/localization in human breast cancer patients. Immunohistochemical analysis of ADA3 expression in breast cancer tissue specimens showed that predominant nuclear ADA3 expression correlated with ER expression and predicted a favorable clinical outcome while predominant ADA3 expression in the cytoplasm correlated with ErbB2+/EGFR+ expression and predicted poorer patient survival as compared to tumors showing ErbB2+ or EGFR+ alone. These results suggest a potential prognostic value of ADA3 expression in breast cancer.

\section{Materials and methods}

Patient population and tissue microarrays

Tissue microarrays (TMAs) were prepared from formalinfixed, paraffin-embedded tissue specimens that include a series of primary operable (stage I and II) breast carcinoma cases of age $<70$ presented consecutively between 1988 and 1998 at the Nottingham Breast Unit with tumors of less than $5 \mathrm{~cm}$ diameter [22]. This is a well-characterized series (900 cases) that includes clinical and pathological data [23]. The breast cancer specific survival (BCSS) is defined as time (in months) from the date of primary surgery to the date of breast cancer-related death. Distant metastasis free survival (DMFS) is defined as duration (in months) from the date of primary surgery to the appearance of distant metastasis. The median age of patients was 55 years (range 18-70 years) with a median BCSS of 129 months (range 4-243 months) and median time of DMFS of 114 months (range 5-241 months). Distant recurrence occurred in 249 cases (31\%); 228 (29\%) patients died from breast cancer, while 435 (56\%) patients were alive at the end of followup. Adjuvant systemic therapies were provided according to the Nottingham Prognostic Index (NPI) group. Systemic therapy was prescribed to the Excellent (NPI $\leq 3.4)$ and Good (NPI 3.41-5.4) prognostic Groups. The Moderate I 
group received hormonal therapy for ER+ tumors. The Moderate II, Poor, and Very Poor Groups received hormone therapy for ER+ tumors and cytotoxic therapy for ER-. Of the informative cases $(n=801) 360$ have received hormone therapy ( $45 \%$ ) while 201 cases received chemotherapy $(25 \%)$. None of the patients received neoadjuvant therapy or anti-HER 2 targeted therapy. The major characteristics of the patient cohort analyzed in this study are summarized in Supplementary Table 1.

\section{Validation of ADA3 antibody specificity in IHC}

We have recently generated anti-ADA3 monoclonal antibody that specifically recognizes human and mouse ADA3 in western blotting and immunoprecipitation [24]. To validate the specificity of monoclonal anti-ADA3 antibody 5C9/C8 in IHC analyses, 76N-TERT cells (hTERTimmortalized normal human mammary epithelial cells-hMECs) or a retroviral transductant overexpressing FLAG-hADA3 as well as mouse embryonic fibroblasts (MEFs) derived from $A d a 3^{f l f l}$ mice [24] infected with a control adenovirus or adenoviral Cre (Ada $\left.{ }^{-/-} \mathrm{MEFs}\right)$ were cultured on coverslips, fixed with $4 \%$ paraformaldehyde, and immunostained with anti-ADA3 antibody, using the procedure described previously [25]. Western blotting was performed on whole cell lysates with a 1:4,000 dilution of anti-ADA3 antibody [24]. Breast cancer TMAs were immunostained as described previously [25].

\section{Scoring of TMA cores}

Of the 900 breast cancer samples analyzed as TMAs, sufficient tissue was available to perform scoring in 803 cases and these form the basis of analyses presented in this study. Normal controls included 25 normal human breast tissue specimens. Semi-quantitative assessment of staining intensity utilized a modified histochemical score (H-score) that includes the intensity of staining and the percentage of stained cells. The intensity of staining was scored on a scale of 0 to 3 corresponding to negative (0), weak (1), moderate (2), and strong (3) staining. Percentage of positive cells was visually estimated. Multiplication of the two indices (intensity and percentage positive cells) provided final scores that range from 0 to 300 . The pattern of expression was visually recorded as nuclear, cytoplasmic, or combined nuclear and cytoplasmic or no nuclear/cytoplasmic staining. Any nuclear expression $(>1 \% ; 41 \%$ cases) was considered positive, while cytoplasmic expression was considered positive if it exceeded a cut-off of an $\mathrm{H}$-score of 110, which is based on histogram distribution of the cases as well as X-Tile computer software analysis [26] (Table 1). All cases were scored without prior knowledge of the clinicopathological parameters or outcome data. In
Table 1 Nuclear and cytoplasmic expression of ADA3 in breast cancer tissue specimens

\begin{tabular}{llll}
\hline $\begin{array}{l}\text { ADA3 nuclear } \\
\text { expression }\end{array}$ & $\begin{array}{l}\text { ADA3 cytoplasmic } \\
\text { expression }\end{array}$ & Total \\
\cline { 2 - 3 } & Negative & Positive & \\
\hline Negative & $50(6.3 \%)$ & $427(53.3 \%)$ & $477(59.6 \%)$ \\
Positive & $103(12.9 \%)$ & $221(27.5 \%)$ & $324(40.4 \%)$ \\
Total & $153(19.2 \%)$ & $648(80.8 \%)$ & 801 \\
\hline
\end{tabular}

tables and figures cytoplasmic positive include cytoplasmic positive cases despite of nuclear-negativity or positivity; similarly nuclear positive cases include nuclear positive regardless of cytoplasmic staining status.

\section{Statistical analysis}

Statistical analysis was performed using the SPSS 16.0 statistical software (SPSS Inc., Chicago, IL, USA). The cut-off values for various biomarkers included in this study were the same as previously published for this patient series $[27,28]$. Optimal cut-offs for ADA3 expression were determined using the X-tile bioinformatics software (version 3.6.1, 2003-2005, Yale University, USA). Analysis of categorical variables was performed with $\chi^{2}$ test. Survival curves were analyzed using the Kaplan-Meier method with significance determined by the Log Rank test. Multivariate analysis was performed using the Cox hazard analysis. A $p$ value (two-sided) of $<0.05$ was considered significant.

\section{Results}

Validation of the specificity of anti-ADA3 monoclonal antibody for IHC

In order to assess the robustness and specificity of this antibody, IHC analysis was performed on 76N-TERT cell line that overexpresses FLAG-hADA3. As expected, essentially no staining was observed with the $\mathrm{IgG}$ negative control, whereas vector-infected cells showed majority nuclear and weak cytoplasmic ADA3 staining as compared to ADA3-overexpressing cell line in which, both strong nuclear and strong cytoplasmic signal was observed (Supplementary Fig. 1a). Western blotting showed high ADA3 expression that correlated with IHC staining (Supplementary Fig. 1b). Next, we used Ada3-null mouse embryonic fibroblasts (MEFs) by adenovirus-Cre infection of $A d a 3^{f / f l}$ MEFs [24]. While specific ADA3 staining was seen in parental $A d a 3^{f l / f}$ MEFs, no staining was seen in MEFs with Cre-induced Ada3 deletion (Supplementary Fig. 1c, d). Altogether, these initial studies validated the use of mAb 5C9/C8 for IHC-based detection of ADA3. 
ADA3 protein is localized to both nucleus and cytoplasm in breast cancer tissue specimens

Next, we carried out IHC analysis of ADA3 expression in TMAs. In normal breast tissue specimens, heterogeneous ADA3 expression was observed in both epithelial and myoepithelial cells lining the ducts (Fig. 1a). Across the panel of breast cancer specimens, ADA3 in tumor cells was variable in degree and site of expression (Fig. 1 b, c, d, e). In tumor tissues four patterns of ADA3 staining were observed as either strong nuclear as in normal ducts (Fig. 1b), strong cytoplasmic (Fig. 1c), strong nuclear and cytoplasmic (Fig. 1d) or barely detectable staining (Fig. 1e). Therefore, we assessed ADA3 expression as strong cytoplasmic (cytoplasmic + ), strong nuclear (nuclear + ), or completely absent in malignant cells (Table 1). Overall, predominant nuclear, cytoplasmic, and mixed (cytoplasmic + nuclear) ADA3 staining was seen in 13,53 , and $28 \%$ of the 801 breast cancer specimens analyzed, respectively. Notably, about $6 \%$ specimens showed a complete absence of ADA3 expression (Table 1).

Correlation of ADA3 expression with clinicopathological parameters

Next, we assessed the association of nuclear and cytoplasmic ADA3 expression with clinicopathological variables (Table 2). Nuclear ADA3 expression was associated with more differentiated tumors (grade 1 and 2), lower degree of cellular pleomorphism $(p \leq 0.001)$, low proliferation status, the absence of vascular invasion $(p=0.008)$, and excellent to good NPI. On the other hand, cytoplasmic ADA3 expression was associated with morphological and molecular features of aggressive behavior in cancer including a higher histological grade (grade 3 ), a high degree of cellular pleomorphism/nuclear atypia ( $p \leq 0.001$ ), and high proliferation status, positive vascular invasion, and poorer NPI (Table 2). Regarding ADA3 expression and tumor subtypes, invasive lobular carcinoma, which are usually ER-positive (>90\% ER+), showed more frequent nuclear expression and less cytoplasmic positivity compared to invasive ductal carcinomas/no special type (Table 3 ).

Association of ADA3 expression with established breast cancer biomarkers

Next, we correlated ADA3 localization with known biomarkers (Table 4). Predominant nuclear ADA3 staining showed a strong positive association with ER and PR positive status $(p<0.001,<0.001)$; positive staining for BRCA1 $(p<0.001)$, a known tumor suppressor in breast cancer $[29,30]$; and with positive staining for cytokeratin 18 ( $p=0.004)$, a luminal marker. However, no correlation with cytokeratin 19 ( $p=0.08)$, a marker of more differentiated luminal cells was observed (Table 4). These results indicate a positive association between nuclear ADA3 staining and positive staining for markers of ER+ luminal breast cancers.

Notably, predominant cytoplasmic ADA3 staining showed a negative association with $\mathrm{ER}(p<0.001)$ and PR $(p=0.005)$ but a positive association with HER2 $(p=0.024)$ and EGFR $(p=0.011)$ positivity. Consistently, predominant cytoplasmic ADA3 staining showed a positive association with increased tumor growth fraction,

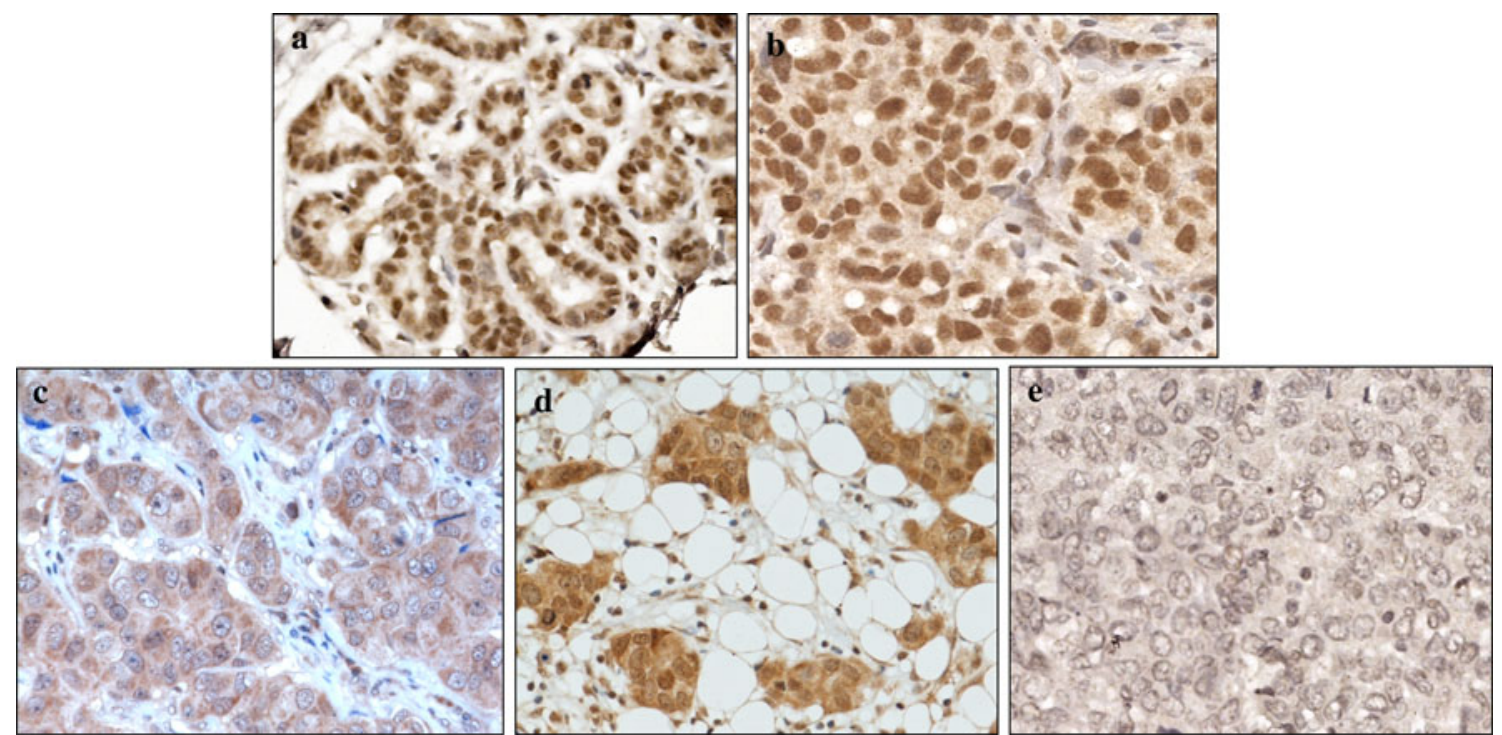

Fig. 1 ADA3 expression in representative normal and breast cancer tissue sections. ADA3 staining of normal breast tissue showing a basal level of nuclear ADA3 expression (a), breast cancer specimens showing only predominantly nuclear (b), predominantly cytoplasmic (c) strong nuclear and cytoplasmic (d) and no staining of ADA3 (e) (magnification $\mathbf{a}$ and $\mathbf{d} \times 20$ and $\mathbf{b}$, $\mathbf{c}$ and $\mathbf{e}$ are $\times 40$ ) 
Table 2 Relationship between ADA3 expression and clinicopathological parameters

\begin{tabular}{|c|c|c|c|c|c|c|}
\hline \multirow[t]{2}{*}{ Variables } & \multicolumn{3}{|c|}{ ADA3 nuclear expression } & \multicolumn{3}{|c|}{ ADA3 cytoplasmic expression } \\
\hline & $\begin{array}{l}\text { Negative } \\
N(\%)\end{array}$ & $\begin{array}{l}\text { Positive } \\
N(\%)\end{array}$ & $p$ value & $\begin{array}{l}\text { Negative } \\
N(\%)\end{array}$ & $\begin{array}{l}\text { Positive } \\
N(\%)\end{array}$ & $p$ value \\
\hline \multicolumn{7}{|l|}{ Patient age } \\
\hline Mean (range) years & $55(28-69)$ & $54(18-70)$ & 0.500 & $56(28-70)$ & $54(18-70)$ & 0.133 \\
\hline \multicolumn{7}{|l|}{ Menopausal status } \\
\hline Premenopausal & $180(38.1)$ & $108(33.8)$ & & $43(28.5)$ & $247(38.4)$ & \\
\hline Postmenopausal & $293(61.9)$ & $212(66.2)$ & 0.216 & $108(71.5)$ & 397 (61.6) & 0.023 \\
\hline \multicolumn{7}{|l|}{ Tumor size $(\mathrm{cm})$} \\
\hline$\leq 1.5$ & $98(20.7)$ & $92(28.3)$ & & $36(23.8)$ & $155(24)$ & \\
\hline$>1.5$ & $375(79.3)$ & $233(71.7)$ & 0.013 & $115(76.2)$ & $490(76)$ & 0.961 \\
\hline \multicolumn{7}{|l|}{ Lymph node stage } \\
\hline 1 & $261(55.2)$ & $195(60)$ & & $97(64.2)$ & $358(55.5)$ & \\
\hline 2 & $160(33.8)$ & $104(32)$ & & $38(25.2)$ & $225(34.9)$ & \\
\hline 3 & $52(11)$ & $26(8)$ & 0.254 & $16(10.6)$ & $62(9.6)$ & 0.072 \\
\hline \multicolumn{7}{|l|}{ Tumor grade } \\
\hline 1 & $51(10.8)$ & 68 (20.9) & & 24 (15.9) & 95 (14.7) & \\
\hline 2 & $136(28.8)$ & $134(41.2)$ & & $72(47.7)$ & $198(30.7)$ & \\
\hline 3 & $286(60.5)$ & $123(37.8)$ & $<0.001$ & $55(36.4)$ & $352(54.6)$ & $<0.001$ \\
\hline \multicolumn{7}{|l|}{ Mitotic counts } \\
\hline 1 & $121(26.3)$ & $138(44.4)$ & & 78 (54.2) & $182(29)$ & \\
\hline 2 & $81(17.6)$ & $64(20.6)$ & & $19(13.2)$ & $126(20.1)$ & \\
\hline 3 & $258(56.1)$ & $109(35)$ & $<0.001$ & $47(32.6)$ & $319(50.9)$ & 0.001 \\
\hline \multicolumn{7}{|l|}{ NPI } \\
\hline Poor & $107(22.6)$ & $118(36.3)$ & & $16(10.6)$ & $128(19.8)$ & \\
\hline Moderate & $266(56.2)$ & $170(52.3)$ & & $78(51.7)$ & $356(55.2)$ & \\
\hline Good & $100(21.1)$ & $118(36.3)$ & $<0.001$ & $57(37.7)$ & $161(25)$ & 0.001 \\
\hline \multicolumn{7}{|l|}{ Distance Metastasis } \\
\hline No & $313(66.7)$ & $228(70.8)$ & & $112(74.7)$ & $428(67)$ & \\
\hline Positive & $156(33.3)$ & $94(29.2)$ & 0.226 & $38(25.3)$ & $211(33)$ & 0.068 \\
\hline \multicolumn{7}{|l|}{ Regional recurrence } \\
\hline No & $412(89.2)$ & $281(88.9)$ & & $130(88.4)$ & $561(89.2)$ & \\
\hline Positive & $50(10.8)$ & $35(11.1)$ & 0.911 & 17 (11.6) & $68(10.8)$ & 0.792 \\
\hline \multicolumn{7}{|l|}{ Vascular invasion } \\
\hline No & $241(56.3)$ & $183(66.3)$ & & 99 (75.6) & $324(56.7)$ & \\
\hline Positive & $187(43.7)$ & 93 (33.7) & 0.008 & $32(24.4)$ & $247(43.3)$ & $<0.001$ \\
\hline
\end{tabular}

previously assessed on full face tissue sections using MIB1 labeling index $(p<0.001)$, p53 $(p=0.001)$, and basal cytokeratin CK17 ( $p=0.007)$. However, no association was observed between cytoplasmic ADA3 staining and CK5/6, CK14, and p63 positivity (myoepithelial/basal markers) (Table 4). These results suggest a strong correlation of predominant cytoplasmic ADA3 staining with ErbB2 and EGFR expressing breast cancers.

Pattern of ADA3 expression in breast cancer tissue predicts patient outcome

Next, we assessed if ADA3 staining patterns could independently predict the patient outcomes. These analyses showed that tumors which lacked predominant nuclear ADA3 staining were associated with reduced BCSS ( $p=0.036$ ) as compared to those showing nuclear ADA3 staining (Fig. 2a). Conversely, patients with predominant cytoplasmic ADA3 staining in breast tumor tissues showed reduced BCSS compared to those that did not show predominant cytoplasmic ADA3 staining $(p=0.031)$ (Fig. 2b). Patients with negative nuclear ADA3 staining or positive cytoplasmic ADA3 staining in tumors showed a trend toward shorter DMFS; however, the association was not statistically significant $(p=0.063$ and $p=0.050$, respectively) (data not shown). Furthermore, multivariate analyses including other prognostic factors (i.e., grade, nodal status, size, and vascular invasion) showed that 
Table 3 Correlations of ADA3 expression with breast cancer histological subtypes

\begin{tabular}{|c|c|c|c|c|c|c|}
\hline \multirow[t]{2}{*}{ Tumor type } & \multicolumn{3}{|c|}{ ADA3 cytoplasmic expression } & \multicolumn{3}{|c|}{ ADA3 nuclear expression } \\
\hline & Negative $N(\%)$ & Positive $N(\%)$ & $p$ value & Negative $N(\%)$ & Positive $N(\%)$ & $p$ value \\
\hline Invasive ductal/no special type (NST) & $60(41)$ & $411(65)$ & & $321(70)$ & $152(48)$ & \\
\hline Invasive lobular & $46(31)$ & $41(7)$ & & $33(7)$ & $53(17)$ & \\
\hline Mixed NST and lobular & $10(7)$ & $19(3)$ & & $13(3)$ & $16(5)$ & \\
\hline Mixed NST and a special type & $2(1)$ & $14(2)$ & & $18(4)$ & $12(4)$ & \\
\hline Tubular mixed & $22(15)$ & $114(18)$ & & $65(14)$ & $71(23)$ & \\
\hline Tubular & $2(1)$ & $18(3)$ & & $10(2)$ & $10(3)$ & \\
\hline Mucinous & $0(0)$ & $4(1)$ & & $2(1)$ & $2(1)$ & \\
\hline Total & 148 & 629 & $<0.001$ & 462 & 316 & $<0.001$ \\
\hline
\end{tabular}

ADA3 was not an independent predictor of BCSS or DMFS (Data not shown).

Notably, combination of predominant nuclear ADA3 staining and ER+ status was associated with a better outcome as compared to patients whose tumors lacked nuclear ADA3 staining and were ER-negative $(p=0.002$ and $p=0.014$ for BCSS and DMFS, respectively) (Fig. 2c, d). On the other hand, predominant cytoplasmic ADA3 staining in ER-negative tumors was associated with shorter survival time as compared to ER+ tumors that did not show predominant cytoplasmic ADA3 staining ( $p=0.002$ and $p=0.014$, respectively) (Fig. 2e, f).

Interestingly, analysis of the whole patient series revealed an association of predominant cytoplasmic ADA3 staining with shorter survival outcome among patients treated with hormone therapy $(p=0.022$ and $p=0.036$ for BCSS and DMFS, respectively), but not among patients that were not given hormone therapy. In contrast, the association of predominant nuclear ADA3 staining with a longer survival outcome was only seen in patients that did not receive hormone therapy ( $p=0.004$ and $p=0.007$ for BCSS and DMFS, respectively).

Next, we assessed if cytoplasmic expression of ADA3 predicts different outcomes in HER2/ErbB2+ and EGFR+ patients. These analyses revealed a significantly worse BCSS in HER2/ErbB2+ and EGFR+ patients that expressed high levels of cytoplasmic ADA3 ( $p=0.000$, $p=0.011$, respectively) compared to those that did not overexpress cytoplasmic ADA3 (Fig. 2g, h). Similarly, HER2/ErbB2 + patients and EGFR+ patients with high cytoplasmic ADA3 showed significantly reduced DMFS ( $p=0.000, p=0.0048$, respectively) (Fig. $2 \mathrm{i}, \mathrm{j}$ ). Due to a small number of patients (total 8-12) available in HER2+/ EGFR+/cytoplasmic ADA3-, we were unable to assess the correlation of this group with BCSS and DMFS (data not shown). Taken together, cytoplasmic ADA3 predicts poorer prognosis and outcome in HER2/ErbB2+ and EGFR + patients. Taken together, these results show that the localization of ADA3 staining in tumor tissues predicts the survival outcomes among breast cancer patients.

\section{Discussion}

Both clinicopathological markers and molecular classification have clearly indicated that breast cancer is a heterogeneous disease with distinct clinical outcomes [2, 31]. While the existing predictive markers have vastly improved our ability to manage breast cancer patients and improved outcomes by matching therapeutic strategies with the types of breast cancer and existence of risk factors, it has also become evident that additional markers are needed to improve patient outcomes. In this study, we have focused on ADA3 expression and subcellular localization in breast cancer as a potential biomarker. Interest in ADA3 emanates from our prior studies that have established the requirement of this evolutionarily conserved component of HAT coactivator complexes for transcriptional activation by ER and other nuclear hormone receptors as well as by other transcription factors [20, 21, 32, 33]. As a known coactivator of ER-dependent transcriptional activation, investigation of ADA3 was of particular interest as $70-80 \%$ of breast cancers are ER + and a large proportion of these patients respond to hormonal therapies targeting estrogen generation or response machinery [11, 34, 35]. Furthermore, other studies have demonstrated that the expression of other ER coactivators such as SRC-3 correlates with disease outcome, including response to hormonal therapy [11]. Here, we show that tumors frequently express predominant ADA3 either in the nucleus or cytoplasm, and that these discrete localizations correlate with ER positivity and HER2/ErbB2 overexpression, respectively. Importantly, nuclear ADA3 expression in ER+ breast cancers predicts more favorable clinical outcomes (BCSS \& DMFS), while lack of nuclear ADA3 expression in ER+ tumors was associated with poorer outcomes. In contrast, 
Table 4 Relationship between ADA3 expression and other biomarkers

\begin{tabular}{|c|c|c|c|c|c|c|}
\hline \multirow[t]{2}{*}{ Variables } & \multicolumn{3}{|c|}{ ADA3 nuclear expression } & \multicolumn{3}{|c|}{ ADA3 cytoplasmic expression } \\
\hline & Negative $N(\%)$ & Positive $N(\%)$ & $p$ value & Negative $N(\%)$ & Positive $N(\%)$ & $p$ value \\
\hline \multicolumn{7}{|c|}{ Hormone receptor } \\
\hline \multicolumn{7}{|l|}{ ER } \\
\hline Negative & $157(34.3)$ & $49(15.7)$ & & $20(13.7)$ & $184(29.6)$ & \\
\hline Positive & $301(65.7)$ & $263(84.3)$ & $<0.001$ & $126(86.3)$ & $438(70.4)$ & $<0.001$ \\
\hline \multicolumn{7}{|l|}{ PgR } \\
\hline Negative & $218(48.7)$ & $230(51.3)$ & & $45(31.7)$ & $274(44.6)$ & \\
\hline Positive & $102(33)$ & $207(67)$ & $<0.001$ & $97(68.3)$ & $340(55.4)$ & 0.005 \\
\hline \multicolumn{7}{|l|}{ ER PgR } \\
\hline $\mathrm{ER}+\mathrm{PR}-$ & $65(14.8)$ & $52(17.3)$ & & $24(17.3)$ & $93(15.5)$ & \\
\hline $\mathrm{ER}-\mathrm{PR}-$ & $147(33.5)$ & $43(14.3)$ & & $18(12.9)$ & $171(28.5)$ & \\
\hline $\mathrm{ER}+\mathrm{PR}+$ & $223(50.8)$ & $202(67.3)$ & & $95(68.3)$ & $330(55.1)$ & \\
\hline $\mathrm{ER}-\mathrm{PR}+$ & $4(1)$ & $3(1)$ & $<0.001$ & $2(1.4)$ & $5(0.8 \%)$ & 0.002 \\
\hline \multicolumn{7}{|l|}{ HER2 } \\
\hline Negative & $386(83.5)$ & $282(88.4)$ & & $131(91.6)$ & $537(84.3)$ & \\
\hline Positive & $76(16.5)$ & 37 (11.6) & 0.058 & $12(8.4)$ & $100(15.7)$ & 0.024 \\
\hline \multicolumn{7}{|c|}{ Triple negative } \\
\hline Non-TN & 352 (76.7) & $282(90.1)$ & & $130(89)$ & $503(80.5)$ & \\
\hline $\mathrm{TN}$ & $107(23.3)$ & $31(9.9)$ & $<0.001$ & $16(11)$ & $122(19.5)$ & 0.015 \\
\hline \multicolumn{7}{|l|}{ BRCA1 } \\
\hline Negative & $221(57.6)$ & $74(28.1)$ & & $43(35.5)$ & $251(47.8)$ & \\
\hline Positive & $163(42.4)$ & 189 (71.9) & $<0.001$ & $78(64.5)$ & $274(52.2)$ & 0.015 \\
\hline \multicolumn{7}{|l|}{ MIB1 } \\
\hline Negative & $102(27.8)$ & $128(47.9)$ & & $63(56.3)$ & $168(32.2)$ & \\
\hline Positive & $265(72.2)$ & $139(52.1)$ & $<0.001$ & $49(43.8)$ & $355(67.8)$ & $<0.001$ \\
\hline \multicolumn{7}{|l|}{ EGFR } \\
\hline Negative & $326(79.5)$ & 237 (87.5) & & $114(90.5)$ & $448(81)$ & \\
\hline Positive & $84(20.5)$ & $34(12.5)$ & 0.007 & $12(9.5)$ & 105 (19) & 0.011 \\
\hline \multicolumn{7}{|l|}{ p63 } \\
\hline Negative & 442 (98.7) & 313 (99.7) & & 143 (98.6) & $611(99.2)$ & \\
\hline Positive & $6(1.3)$ & $1(0.3)$ & 0.146 & $2(1.4)$ & $5(0.8)$ & 0.519 \\
\hline \multicolumn{7}{|l|}{ p53 } \\
\hline Negative & 302 (67.7) & $241(78)$ & & $118(83.1)$ & 425 (69.4) & \\
\hline Positive & $144(32.3)$ & $68(22)$ & 0.002 & $24(16.9)$ & 187 (30.6) & 0.001 \\
\hline \multicolumn{7}{|l|}{ Cytokeratins } \\
\hline \multicolumn{7}{|l|}{ CK 5/6 } \\
\hline Negative & $378(84)$ & 268 (87.9) & & 125 (87.9) & $521(85.1)$ & \\
\hline Positive & $72(16)$ & $37(12.1)$ & 0.138 & $17(12.1)$ & $92(15)$ & 0.369 \\
\hline \multicolumn{7}{|l|}{ CK 14} \\
\hline Negative & 407 (90.6) & $271(89.1)$ & & $132(93)$ & $546(89.8)$ & \\
\hline Positive & $42(9.4)$ & $31(10.2)$ & 0.68 & $10(7)$ & $62(10.2)$ & 0.251 \\
\hline \multicolumn{7}{|l|}{ CK 17} \\
\hline Negative & 332 (87.4) & 214 (87.7) & & 112 (94.9) & 433 (85.7) & \\
\hline Positive & 48 (12.6) & $30(12.3)$ & 0.901 & $6(5.1)$ & $72(14.3)$ & 0.007 \\
\hline \multicolumn{7}{|l|}{ CK 18} \\
\hline Negative & 73 (17) & $27(9.5)$ & & $18(13.3)$ & $81(14)$ & \\
\hline Positive & $356(83)$ & $258(90.5)$ & 0.004 & $118(86.8)$ & $497(86)$ & 0.813 \\
\hline
\end{tabular}


Table 4 continued

\begin{tabular}{|c|c|c|c|c|c|c|}
\hline \multirow[t]{2}{*}{ Variables } & \multicolumn{3}{|c|}{ ADA3 nuclear expression } & \multicolumn{3}{|c|}{ ADA3 cytoplasmic expression } \\
\hline & Negative $N(\%)$ & Positive $N(\%)$ & $p$ value & Negative $N(\%)$ & Positive $N(\%)$ & $p$ value \\
\hline \multicolumn{7}{|l|}{ CK 19} \\
\hline Negative & $49(10.7)$ & $22(7)$ & & $11(7.5)$ & $59(9.5)$ & \\
\hline Positive & 408 (89.3) & $292(93)$ & 0.08 & $135(92.5)$ & $565(90.5)$ & 0.467 \\
\hline
\end{tabular}

cytoplasmic ADA3 expression in ErbB2/EGFR-overexpressing breast cancers was associated with a poorer outcome. Thus, our studies suggest that ADA3 expression and its nuclear vs. cytoplasmic compartmentalization in tumor cells can serve as a prognostic marker to facilitate management of breast cancer patients.

To assess the expression of ADA3 in breast cancer, we first established the ability of a $\mathrm{mAb}$ recently generated in our laboratory to specifically detect the expression of human ADA3 in an IHC format. By utilizing Ada $3^{f / f t}$ versus Ada3-null MEFs, through conditional deletion of floxed Ada3 [24] and human mammary epithelial cells with ectopic overexpression of a FLAG-tagged ADA3 versus vector controls, we established the ability of our mAb antiADA3 to specifically detect ADA3 and to provide an assessment of levels and localization of ADA3 expression in a cell-based IHC.

Using TMAs generated from a large cohort of breast cancer tissue specimens with known clinicopathological parameters and survival data and a panel of normal breast tissues, we first demonstrated that while basal level of both nuclear and cytoplasmic ADA3 was seen in breast duct epithelial cells, about $81 \%$ of breast cancer specimens showed prominent strong cytoplasmic ADA3 staining, either exclusively or together with nuclear staining, while $13 \%$ of tumors exhibited predominantly strong nuclear ADA3 staining.

The mechanisms that regulate nuclear/cytoplasmic partitioning of ADA3 under physiological conditions remain unknown and any alterations of such processes in breast cancer tissues remain a matter of speculation at present. The presence of five potential nuclear hormone binding LXXLL motifs and a predicted nuclear localization signal (NLS) in ADA3 led to earlier studies that demonstrated the role of ADA3 as a coactivator for $\mathrm{ER}$ and $\mathrm{RXR}[20,36]$. Interestingly, the well-known ER coactivator SRC-3 is known to undergo estrogen-induced phosphorylation in the cytoplasm followed by its transport to the nucleus [37, 38], suggesting that phosphorylation of coactivators may determine their nuclear localization. Publicly available proteomics datasets indicate that ADA3 can undergo several post-translational modifications including phosphorylation, acetylation, methylation, and ubiquitination, all of which can affect subcellular localization of proteins.
Potential structural alterations of the putative NLS or posttranslational modifications could alter ADA3 localization in breast cancer cells and these will be of considerable future interest to explore.

Notably, about $6 \%$ of breast cancer specimens analyzed showed undetectable ADA3 staining. At this time, the potential mechanisms of the reduction/loss of ADA3 expression in this subset of breast tumors remain unknown. In addition to altered post-translational modifications, discussed above in relation to localization, reduced ADA3 expression can be due to genetic and/or epigenetic alterations. If future studies validate the reduction in ADA3 expression that we observed, albeit in a small subset of breast cancers, it will be of considerable biological interest to assess if such tumors have an activation of alternate pathways that compensate for ADA3 functions. Such compensation is suggested by our studies with genetic knockout of ADA3: deletion of ADA3 in mouse germline induces early embryonic lethality and its conditional deletion in mouse embryonic fibroblasts induces cell cycle block [24]. These findings suggest that loss of ADA3 in tumors might be compensated by upregulation of an alternate functional pathway since mammals do not possess a close structural homolog of ADA3. Furthermore, our recent studies demonstrated that a loss of ADA3 induces genomic instability and delay in DNA repair process [39], underscoring the role of ADA3 in oncogenesis.

Although in multivariate analyses ADA3 expression was not an independent marker of survival; all ER-positive breast cancer specimens revealed the presence of nuclear ADA3 and predicted good prognosis as compared to breast cancers where ADA3 was cytoplasmic. Furthermore, nuclear staining of ADA3 was significantly associated with BRCA1 expression, which is a known tumor suppressor in breast cancer [29, 30], and was significantly associated with cytokeratin 18, a luminal marker. Thus, predominant nuclear ADA3 expression is correlated with luminal ERpositive breast cancers. Interestingly, nuclear SRC-3 expression also correlates with the luminal ER+ subtype of breast cancer [18].

Somewhat unexpectedly, predominant cytoplasmic ADA3 staining was seen in a substantial subset of breast cancers and correlated with higher tumor size, histological grade, MIB1 expression, increased mitotic count, positive 

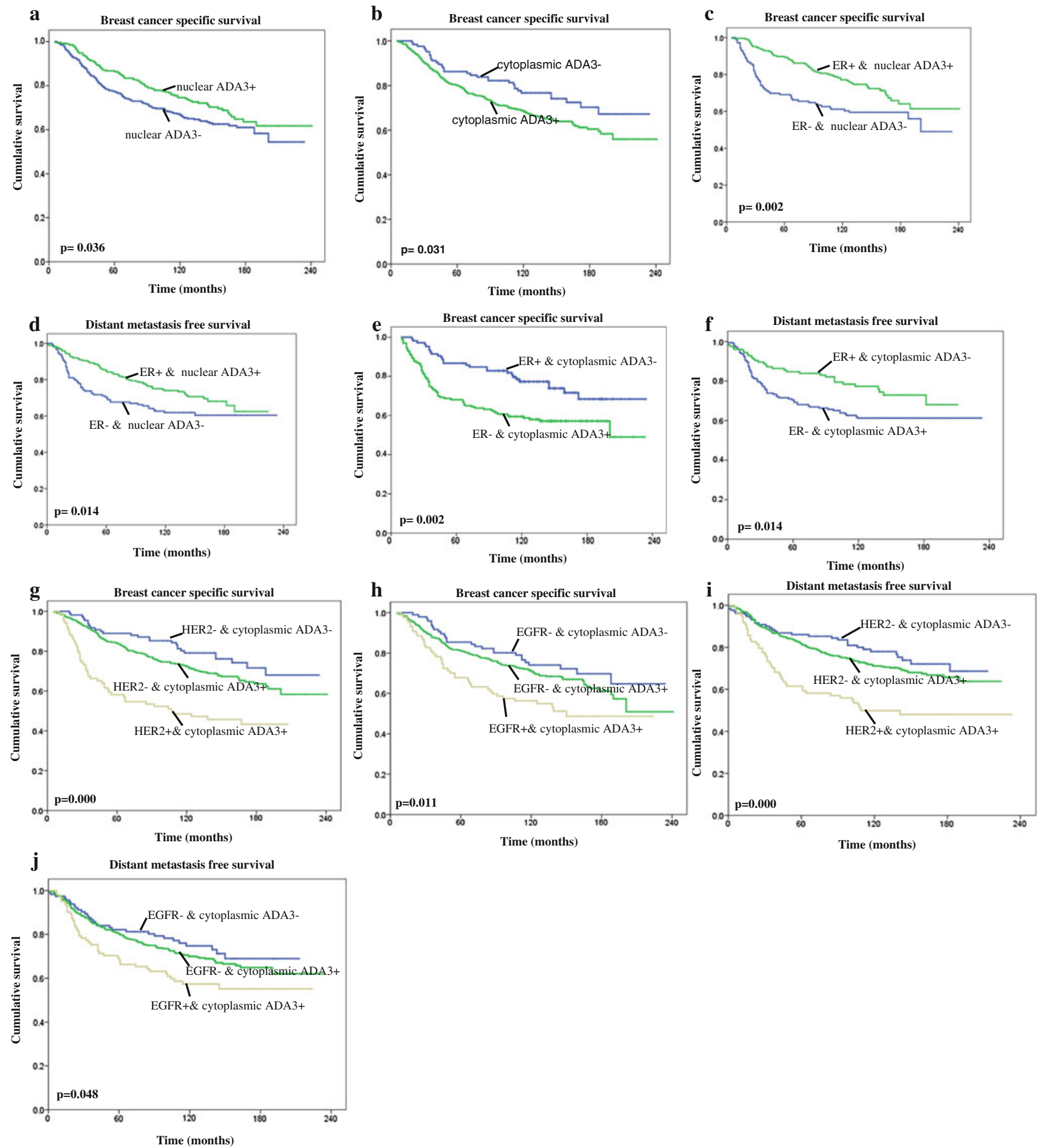

Fig. 2 Kaplan-Meier plot of nuclear (a) or cytoplasmic (b) ADA3 expression in the whole series of breast cancer patients with respect to BCSS for 250 months. Kaplan-Meier plot of association of ADA3 nuclear $(\mathbf{c}, \mathbf{d})$, and ADA3 cytoplasmic $(\mathbf{e}, \mathbf{f})$ expression and ER

vascular invasion, and higher NPI, all well-known markers associated with poor prognosis. Given the negative correlation of cytoplasmic ADA3 staining with ER+ status, we sought to determine if cytoplasmic ADA3 correlates with expression in the whole series of breast cancer patients with respect to BCSS and DMFS for 250 months. Kaplan-Meier plot of breast cancer patients with cytoplasmic ADA3 and HER2/ErbB2 (g) or EGFR (h) with respect to BCSS $(\mathbf{g}, \mathbf{h})$ and DMFS $(\mathbf{i}, \mathbf{j})$ for 250 months

other biological markers that predict distinct outcomes. Significantly, cytoplasmic ADA3 staining was positively associated with overexpression of EGFR and ErbB2, markers that predict poor prognosis in breast cancer [40]. 
Significantly, cytoplasmic ADA3 in the HER2/EGFRoverexpressing patients predicted a poorer outcome both in terms of BCSS and DMFS. Thus, additional markers that might improve the prediction of outcomes in ErbB2-overexpressing subset of patients could help physicians and patients in deciding on options for treatment strategies.

While the potential biological links between cytoplasmic ADA3 localization and ErbB2 or EGFR expression remain to be investigated, it is reasonable to speculate a potential role of signaling pathways downstream of EGFR/ ErbB2 in ADA3 localization, possibly through posttranslational modifications of ADA3; alternatively, cytoplasmic ADA3 may modify signaling downstream of EGFR/ErbB2. In this regard, an SRC-3 splice variant SRC- $3 \Delta 4$ is known to promote EGF-induced phosphorylation of FAK and c-Src [41]. Furthermore, overexpression of SRC-3 together with the presence of EGFR/ErbB2 is associated with resistance to tamoxifen therapy and decreased disease-free survival $[42,43]$.

In conclusion, our studies provide evidence that nuclear versus cytoplasmic ADA3 localization serves as a prognostic marker in breast cancer; while predominant nuclear ADA3 localization is associated with ER+ status and markers of good prognosis, predominant cytoplasmic localization is associated with markers of poor prognosis and correlates with EGFR+ and ErbB2+ breast cancer subtypes. In view of our findings, further studies of the biological roles of ADA3 in breast oncogenesis using cellular and animal models together are warranted, as are additional clinical studies with therapeutic outcomes, to help clarify if ADA3 expression can improve prognostication in breast cancer.

Acknowledgments This research is supported by the NIH Grant R01 CA096844 and UNMC startup funds to VB.

Conflict of interest The authors disclose no conflict of interest.

Open Access This article is distributed under the terms of the Creative Commons Attribution Noncommercial License which permits any noncommercial use, distribution, and reproduction in any medium, provided the original author(s) and the source are credited.

\section{References}

1. Jemal A, Bray F, Center MM, Ferlay J, Ward E, Forman D (2011) Global cancer statistics. CA Cancer J Clin 61(2):69-90. doi: 10.3322/caac. 20107

2. Sorlie T, Perou CM, Tibshirani R, Aas T, Geisler S, Johnsen H, Hastie T, Eisen MB, van de Rijn M, Jeffrey SS, Thorsen T, Quist H, Matese JC, Brown PO, Botstein D, Lonning PE, Borresen-Dale AL (2001) Gene expression patterns of breast carcinomas distinguish tumor subclasses with clinical implications. Proc Natl Acad Sci USA 98(19):10869-10874. doi:10.1073/pnas.191367098
3. Hudis CA (2007) Trastuzumab-mechanism of action and use in clinical practice. N Engl J Med 357(1):39-51. doi:10.1056/ NEJMra043186

4. Colditz GA (1998) Relationship between estrogen levels, use of hormone replacement therapy, and breast cancer. J Natl Cancer Inst 90(11):814-823

5. Korach KS, Emmen JM, Walker VR, Hewitt SC, Yates M, Hall JM, Swope DL, Harrell JC, Couse JF (2003) Update on animal models developed for analyses of estrogen receptor biological activity. J Steroid Biochem Mol Biol 86(3-5):387-391

6. Mohibi S, Mirza S, Band H, Band V (2011) Mouse models of estrogen receptor-positive breast cancer. J Carcinog 10:35. doi: 10.4103/1477-3163.91116

7. Petz LN, Nardulli AM (2000) Sp1 binding sites and an estrogen response element half-site are involved in regulation of the human progesterone receptor A promoter. Mol Endocrinol 14(7): 972-985

8. Sabbah M, Courilleau D, Mester J, Redeuilh G (1999) Estrogen induction of the cyclin D1 promoter: involvement of a cAMP response-like element. Proc Natl Acad Sci USA 96(20): $11217-11222$

9. Vyhlidal C, Samudio I, Kladde MP, Safe S (2000) Transcriptional activation of transforming growth factor alpha by estradiol: requirement for both a GC-rich site and an estrogen response element half-site. J Mol Endocrinol 24(3):329-338

10. Johnson AB, O'Malley BW (2011) ERasing breast cancer resistance through the kinome. Nat Med 17(6):660-661. doi:10.1038/ nm0611-660

11. Johnson AB, O'Malley BW (2012) Steroid receptor coactivators 1, 2, and 3: critical regulators of nuclear receptor activity and steroid receptor modulator (SRM)-based cancer therapy. Mol Cell Endocrinol 348(2):430-439. doi:10.1016/j.mce.2011.04.021

12. Xu J, Li Q (2003) Review of the in vivo functions of the p160 steroid receptor coactivator family. Mol Endocrinol 17(9): 1681-1692. doi:10.1210/me.2003-0116me

13. Xu J, Wu RC, O'Malley BW (2009) Normal and cancer-related functions of the p160 steroid receptor co-activator (SRC) family. Nat Rev Cancer 9(9):615-630. doi:10.1038/nrc2695

14. Chakravarti D, LaMorte VJ, Nelson MC, Nakajima T, Schulman IG, Juguilon H, Montminy M, Evans RM (1996) Role of CBP/ P300 in nuclear receptor signalling. Nature 383(6595):99-103. doi:10.1038/383099a0

15. Kamei Y, Xu L, Heinzel T, Torchia J, Kurokawa R, Gloss B, Lin SC, Heyman RA, Rose DW, Glass CK, Rosenfeld MG (1996) A CBP integrator complex mediates transcriptional activation and AP-1 inhibition by nuclear receptors. Cell 85(3):403-414

16. Xu J, Liao L, Ning G, Yoshida-Komiya H, Deng C, O’Malley BW (2000) The steroid receptor coactivator SRC-3 (p/CIP/ RAC3/AIB1/ACTR/TRAM-1) is required for normal growth, puberty, female reproductive function, and mammary gland development. Proc Natl Acad Sci USA 97(12):6379-6384. doi: 10.1073/pnas.120166297

17. Wang Z, Rose DW, Hermanson O, Liu F, Herman T, Wu W, Szeto D, Gleiberman A, Krones A, Pratt K, Rosenfeld R, Glass CK, Rosenfeld MG (2000) Regulation of somatic growth by the p160 coactivator p/CIP. Proc Natl Acad Sci USA 97(25): 13549-13554. doi:10.1073/pnas.260463097

18. Osborne CK, Bardou V, Hopp TA, Chamness GC, Hilsenbeck SG, Fuqua SA, Wong J, Allred DC, Clark GM, Schiff R (2003) Role of the estrogen receptor coactivator AIB1 (SRC-3) and HER-2/neu in tamoxifen resistance in breast cancer. J Natl Cancer Inst 95(5): 353-361

19. Lee KK, Workman JL (2007) Histone acetyltransferase complexes: one size doesn't fit all. Nat Rev Mol Cell Biol 8(4): 284-295. doi:10.1038/nrm2145 
20. Meng G, Zhao Y, Nag A, Zeng M, Dimri G, Gao Q, Wazer DE, Kumar R, Band H, Band V (2004) Human ADA3 binds to estrogen receptor (ER) and functions as a coactivator for ERmediated transactivation. J Biol Chem 279(52):54230-54240. doi:10.1074/jbc.M404482200

21. Germaniuk-Kurowska A, Nag A, Zhao X, Dimri M, Band H, Band V (2007) Ada3 requirement for HAT recruitment to estrogen receptors and estrogen-dependent breast cancer cell proliferation. Cancer Res 67(24):11789-11797. doi:10.1158/00085472.CAN-07-2721

22. Abd El-Rehim DM, Ball G, Pinder SE, Rakha E, Paish C, Robertson JF, Macmillan D, Blamey RW, Ellis IO (2005) High-throughput protein expression analysis using tissue microarray technology of a large well-characterised series identifies biologically distinct classes of breast cancer confirming recent cDNA expression analyses. Int $\mathrm{J}$ Cancer 116(3):340-350. doi:10.1002/ijc.21004

23. Elston CW, Ellis IO (1991) Pathological prognostic factors in breast cancer. I. The value of histological grade in breast cancer: experience from a large study with long-term follow-up. Histopathology 19(5):403-410

24. Mohibi S, Gurumurthy CB, Nag A, Wang J, Mirza S, Mian Y, Quinn M, Katafiasz B, Eudy J, Pandey S, Guda C, Naramura M, Band H, Band V (2012) Mammalian alteration/deficiency in activation 3 (Ada3) is essential for embryonic development and cell cycle progression. J Biol Chem. doi:10.1074/jbc.M112. 378901

25. Zhao X, Mirza S, Alshareeda A, Zhang Y, Gurumurthy CB, Bele A, Kim JH, Mohibi S, Goswami M, Lele SM, West W, Qiu F, Ellis IO, Rakha EA, Green AR, Band H, Band V (2012) Overexpression of a novel cell cycle regulator ecdysoneless in breast cancer: a marker of poor prognosis in HER2/neu-overexpressing breast cancer patients. Breast Cancer Res Treat. doi:10.1007/ s10549-011-1946-8

26. Camp RL, Dolled-Filhart M, Rimm DL (2004) X-tile: a new bioinformatics tool for biomarker assessment and outcome-based cut-point optimization. Clin Cancer Res 10(21):7252-7259. doi: 10.1158/1078-0432.CCR-04-0713

27. Rakha EA, El-Sayed ME, Green AR, Paish EC, Powe DG, Gee J, Nicholson RI, Lee AH, Robertson JF, Ellis IO (2007) Biologic and clinical characteristics of breast cancer with single hormone receptor positive phenotype. J Clin Oncol 25(30):4772-4778. doi: 10.1200/JCO.2007.12.2747

28. Rakha EA, Putti TC, Abd El-Rehim DM, Paish C, Green AR, Powe DG, Lee AH, Robertson JF, Ellis IO (2006) Morphological and immunophenotypic analysis of breast carcinomas with basal and myoepithelial differentiation. J Pathol 208(4):495-506. doi: 10.1002/path.1916

29. Rosen EM, Fan S, Isaacs C (2005) BRCA1 in hormonal carcinogenesis: basic and clinical research. Endocr Relat Cancer 12(3):533-548. doi:10.1677/erc.1.00972

30. Miki Y, Swensen J, Shattuck-Eidens D, Futreal PA, Harshman K, Tavtigian S, Liu Q, Cochran C, Bennett LM, Ding W et al (1994) A strong candidate for the breast and ovarian cancer susceptibility gene BRCA1. Science 266(5182):66-71

31. Perou CM, Sorlie T, Eisen MB, van de Rijn M, Jeffrey SS, Rees CA, Pollack JR, Ross DT, Johnsen H, Akslen LA, Fluge O, Pergamenschikov A, Williams C, Zhu SX, Lonning PE, Borresen-Dale AL, Brown PO, Botstein D (2000) Molecular portraits of human breast tumours. Nature 406(6797):747-752. doi:10.1038/3502 1093
32. Nag A, Germaniuk-Kurowska A, Dimri M, Sassack MA, Gurumurthy CB, Gao Q, Dimri G, Band H, Band V (2007) An essential role of human Ada3 in p53 acetylation. J Biol Chem 282(12):8812-8820. doi:10.1074/jbc.M610443200

33. Zeng M, Kumar A, Meng G, Gao Q, Dimri G, Wazer D, Band H, Band V (2002) Human papilloma virus 16 E6 oncoprotein inhibits retinoic $\mathrm{X}$ receptor-mediated transactivation by targeting human ADA3 coactivator. J Biol Chem 277(47):45611-45618. doi:10.1074/jbc.M208447200

34. Howell A, Robertson JF, Abram P, Lichinitser MR, Elledge R, Bajetta E, Watanabe T, Morris C, Webster A, Dimery I, Osborne CK (2004) Comparison of fulvestrant versus tamoxifen for the treatment of advanced breast cancer in postmenopausal women previously untreated with endocrine therapy: a multinational, double-blind, randomized trial. J Clin Oncol 22(9):1605-1613. doi: $10.1200 / J C O .2004 .02 .112$

35. Dowsett M, Cuzick J, Ingle J, Coates A, Forbes J, Bliss J, Buyse M, Baum M, Buzdar A, Colleoni M, Coombes C, Snowdon C, Gnant M, Jakesz R, Kaufmann M, Boccardo F, Godwin J, Davies C, Peto R (2010) Meta-analysis of breast cancer outcomes in adjuvant trials of aromatase inhibitors versus tamoxifen. J Clin Oncol 28(3):509-518. doi:10.1200/JCO.2009.23.1274

36. Li CW, Ai N, Dinh GK, Welsh WJ, Chen JD (2010) Human ADA3 regulates RARalpha transcriptional activity through direct contact between LxxLL motifs and the receptor coactivator pocket. Nucleic Acids Res 38(16):5291-5303. doi:10.1093/nar/ gkq269

37. Zheng FF, Wu RC, Smith CL, O'Malley BW (2005) Rapid estrogen-induced phosphorylation of the SRC-3 coactivator occurs in an extranuclear complex containing estrogen receptor. Mol Cell Biol 25(18):8273-8284. doi:10.1128/MCB.25.18.82738284.2005

38. Amazit L, Pasini L, Szafran AT, Berno V, Wu RC, Mielke M, Jones ED, Mancini MG, Hinojos CA, O’Malley BW, Mancini MA (2007) Regulation of SRC-3 intercompartmental dynamics by estrogen receptor and phosphorylation. Mol Cell Biol 27(19): 6913-6932. doi:10.1128/MCB.01695-06

39. Mirza S, Katafiasz BJ, Kumar R, Wang J, Mohibi S, Jain S, Gurumurthy CB, Pandita TK, Dave BJ, Band H, Band V (2012) Alteration/deficiency in activation-3 (Ada3) plays a critical role in maintaining genomic stability. Cell Cycle 11(22):4266-4274. doi: $10.4161 /$ cc. 22613

40. Bailey TA, Luan H, Clubb RJ, Naramura M, Band V, Raja SM, Band H (2011) Mechanisms of Trastuzumab resistance in ErbB2driven breast cancer and newer opportunities to overcome therapy resistance. J Carcinog 10:28. doi:10.4103/1477-3163.90442

41. Long W, Yi P, Amazit L, LaMarca HL, Ashcroft F, Kumar R, Mancini MA, Tsai SY, Tsai MJ, O’Malley BW (2010) SRC-3Delta4 mediates the interaction of EGFR with FAK to promote cell migration. Mol Cell 37(3):321-332. doi:10.1016/j.molcel.2010. 01.004

42. Arpino G, Wiechmann L, Osborne CK, Schiff R (2008) Crosstalk between the estrogen receptor and the HER tyrosine kinase receptor family: molecular mechanism and clinical implications for endocrine therapy resistance. Endocr Rev 29(2):217-233. doi: 10.1210/er.2006-0045

43. Lahusen T, Henke RT, Kagan BL, Wellstein A, Riegel AT (2009) The role and regulation of the nuclear receptor co-activator AIB1 in breast cancer. Breast Cancer Res Treat 116(2):225-237. doi: 10.1007/s10549-009-0405-2 